\title{
ПРАВОВОЕ РЕГУЛИРОВАНИЕ ПЕНСИОННОГО ОБЕСПЕЧЕНИЯ ПО СТАРОСТИ В ШВЕЙЦАРИИ: ЧТО ЦЕЛЕСООБРАЗНО УЧЕСТЬ РОССИЙСКОМУ ЗАКОНОДАТЕЛЮ
}

Аннотация: Предметом исследования являются правовые нормы, регулируюшие основания назначения пенсии по старости в рамках обязательного пенсионного страхования в Швейцарии и России. Автор устанавливает, что основанием назначения этого вида пенсии в обеих странах является совокупность юридических фактов - сложный юридический состав, включающий наличие определенного страхового стажа, достижение пенсионного возраста, обращение в компетентный орган за назначением пенсии и принятие этим органом положительного решения, отдельные элементы которого сравниваются автором с целью выявления возможностей совершенствования российского пенсионного обеспечения. Сопоставляя российское и швейцарское пенсионное законодательство, автор в качестве основного метода исследования применяет сравнительно-правовой метод. Автором сделань выводы о необходимости закрепления в российском пенсионном законодательстве цели назначения пенсии для обеспечения пенсионеру достойного уровня жизни, понятия страхового стажа без привязки к уплате страховых взносов в период трудовой или иной оплачиваемой деятельности, увеличения засчитываемого в страховой стаж периода ухода за детьми для совершенствования российского пенсионного законодательства.

Abstract: The object of studies in this article includes the legal norms regulating the grounds for assigning the old age pension within the system of obligatory pension insurance in Switzerland and in Russia. The author establishes that the conditions for provision of this type of pension include a combination of legal facts, being a complicated legal composition. It includes presence of the certain number of years of pensionable service, achieving a pension age, address to a competent body for assigning a pension, and a positive decision of this body, while some of its elements are compared by the author in order to find the possibilities for the improvement of the Russian pension legislation. Comparing Russian and Swiss pension legislation the author uses comparative legal method as the main method for the studies. The author draws a conclusion on the need to provide in the Russian pension legislation the goals for assigning a pension in order to guarantee a retired person a worthy living, definition of years of pensionable service without reference to payment of insurance at the time of work or other paid activities, enlarging the period of childcare which should be included into the years of pensionable service in order to improve the Russian pension legislation.

Ключевые слова: пенсия, пенсия по старости, пенсионное обеспечение, социальное обеспечение, страховой стаж, пенсионная система Швейцарии, обязательное пенсионное страхование, нестраховые периоды, цели пенсионного обеспечения, пенсии работающим пенсионерам.

Keywords: pension, old age pension, pension guarantees, social guarantees, years of pensionable service, pension system of Switzerland, obligatory pension insurance, non-insurance periods, goals of pension guarantees, pensions to working pensioners.

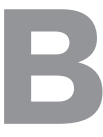

связи с продолжающимся реформированием пенсионной системы России важным и актуальным является исследование пенсионного обеспечения других стран, отличающихся стабильным законодательством и высоким уровнем жизни населения. В этой связи представляется интересным исследование опыта Швейцарии в регулировании правовых оснований обеспечения пенсиями по старости граждан этого государства.
Право на пенсию, назначаемую в рамках пенсионного страхования по старости, закреплено непосредственно в ч.1 ст.111 Конституции Швейцарии 1999 г. Государственной она ни в законодательстве, ни в научной литературе не именуется. Ее традиционное название - «пенсия по старости», хотя понятия «старость» швейцарское законодательство не содержит. 


\section{Право и политика $5(173) \cdot 2014$}

При анализе основного нормативно-правового акта, регулирующего данный вид пенсий, а именно Федерального закона «О страховании по старости и на случай потери кормильца» (далее-Закон 1946 г.), можно выявить следующие признаки швейцарской пенсии по старости. Это пожизненная ежемесячная денежная выплата, назначаемая лицам, достигшим определенного законом возраста и уплачивавшим страховые взносы в течение установленного периода, рассчитываемая исходя из страхового стажа и среднегодового дохода лица, периодически индексируемая в целях приспособления к росту цен.

Ни в Конституции Швейцарии, ни в Законе не определены цели назначения пенсий по старости, в связи с чем обратимся к швейцарскому законодательству. Есть основания полагать, что целью их выплаты является предоставление лицу, достигшему определенного возраста, ежемесячной выплаты, необходимой для поддержания приемлемого уровня жизни - не ниже социального прожиточного минимума.

Подтверждением этого вывода является то, что работающим пенсионерам выплата пенсии не огранивается, независимо от получаемого ими дохода, в отличие от некоторых других европейских стран. Более того, пенсионеры освобождаются от уплаты страховых взносов, в случае, если вышли на пенсию в общеустановленном возрасте. В швейцарском законодательстве в отличие от российского законодательства (ст.2 Федерального закона от 17 декабря 2001 № 173-Ф3 «О трудовых пенсиях в Российской Федерации») не говорится о том, что пенсия по старости имеет целью компенсировать утраченный доход.

На первый взгляд это не имеет для пенсионеров значения. Сейчас пенсия в России назначается и выплачивается независимо от того, прекращает ли пенсионер работу, в том числе и при наличии у Пенсионного фонда РФ данных о том, что он работает, поскольку страховые взносы продолжают отчисляться. Но если исходить из буквального толкования целевого назначения выплаты российской пенсии, то пенсия по старости работающим пенсионерам выплачиваться не должна, так как иной цели ст.2 Закона о трудовых пенсиях не называет. Как справедливо отмечает В.П.Галаганов, компенсационный характер трудовой пенсии ставит под сомнение возможность ее выплаты в будущем пенсионерам, продолжающим работу².

${ }^{1}$ С3 РФ. 2001, № 52 (1 ч.). Ст. 4920. Далее будет именоваться Законом о трудовых пенсиях.

${ }^{2}$ Галаганов В.П. Право социального обеспечения. М., КноРУС. 2010. C.278.
Статья 2 Федерального закона от 28 декабря 2013 № 400-Ф3 «О страховых пенсиях» (далее - Закон о страховых пенсиях) определяя понятие страховой пенсии, фактически повторяет норму ст.2 Закона о трудовых пенсиях, что может привести в будущем к ограничению ее выплаты работающим пенсионерам. Этот вариант недавно активно обсуждался на государственном уровне ${ }^{4}$. Хотя сейчас об ограничении выплаты пенсии работающим пенсионерам речи уже не идет, не исключено, что этот вопрос может возникнуть вновь.

Если обратиться к нормам Конвенции МОТ №102 «О минимальных нормах социального обеспечения» ${ }^{5}$ (далее - Конвенция), то увидим, что там целью пенсионного обеспечения не названа компенсация пенсионеру утраченного дохода. В то же время статья 26 Конвенции устанавливает, что законодательство страны может предусматривать приостановление пенсионного обеспечения лиц, имеющих на него право, но занимающихся какой-либо установленной деятельностью, приносящей доход, а также сокращать размер пенсионного обеспечения, если заработок получающего его лица превышает установленную сумму.

В европейских государствах существуют разные варианты решения вопроса о выплате пенсии работающим пенсионерам. В одних странах не ограничивается право работать и получать пенсию (наряду со Швейцарией к ним относятся Швеция, Кипр, Нидерланды), в других существуют ограничения по получаемому лицом совокупному доходу, состоящему из заработной платы и пенсии (особенно это касается тех стран, где допускается досрочный выход на пенсию). Так, в Бельгии выплата пенсий может быть приостановлена при превышении на $15 \%$ размера предельного совокупного дохода, установленного для работающего пенсионера. В Австрии для лица, вышедшего на пенсию досрочно, установлен предел заработка - не более 333 евро в месяц. Во Франции пенсия и получаемый заработок не должны превышать 160\% прожиточного минимума. В Испании в случае продолжения работы пенсия не выплачивается.

Несмотря на то, что Конвенцией допускается ограничение работающего пенсионера в получении пенсии,

\footnotetext{
${ }^{3}$ Российская газета. 2013. 31.12. № 296. В соответствии со статьей 36 данный документ вступает в силу с 1 января 2015 года, за исключением частей 14 и 15 статьи 17, вступающих в силу с 1 января 2016 года.

${ }^{4}$ Работающих пенсионеров могут ограничить в получении пенсии. Российская газета. 2013. 27. 06. № 6113 (137).

${ }^{5}$ Конвенция ратифицирована Швейцарией и не ратифицирована Российской Федерацией.
} 
это не является повсеместно распространенной практикой в европейских странах.

Разделяя мнение ученых ${ }^{6}$, выступавших против ограничения права получать пенсию работающих лиц, обратим внимание на нормы Конституции РФ. Полагаем, что введение такого правила будет противоречить ее нормам. Во-первых, согласно ст. 37 Конституции РФ труд свободен. Каждый имеет право свободно распоряжаться своими способностями к труду, выбирать род деятельности и профессию. Согласно ст. 7 и ст. 39 Конституции РФ каждому гарантируется социальное обеспечение по возрасту. Запрет получать пенсию при продолжении трудовой деятельности, фактически ставит человека перед выбором: реализовать ли ему право на труд или получать пенсионное обеспечение по возрасту, хотя по Конституции он имеет право на то и другое.

Представляется, в пенсионном законодательстве должно быть четко закреплено, что основной целью пенсионного обеспечения по старости является обеспечение пенсионеру достойного уровня жизни. В этой связи предлагаем в ст. 2 Закона о трудовых пенсиях, в ст.2 Закона о страховых пенсиях представить страховую пенсию как ежемесячную денежную выплату, назначаемую застрахованным лицам при достижении пенсионного возраста, наступлении инвалидности, членам семьи застрахованных лиц в случае потери кормильца в целях предоставления указанным лицам средств для поддержания достойного уровня жизни.

В соответствии с Законом в Швейцарии главным условием учета периода в страховой стаж является уплата лицом, страховым взносом, что не вовсе зависит от осуществления лицом трудовой или иной оплачиваемой деятельности.

В российском пенсионном законодательстве все не так однозначно. Понятие страхового стажа и его связь с трудовой деятельностью различаются в разных законах. Так, согласно ст.2 Закона о трудовых пенсиях, страховой стаж - это учитываемая при определении права на трудовую пенсию суммарная продолжительность периодов работы и (или) иной деятельности, в течение которых уплачивались страховые взносы в Пенсионный фонд Российской Федерации, а также иных периодов, засчитываемых в страховой стаж. В Законе о страховых пенсиях воспроизведено это определение.

Согласно Федеральному закону от 16 июля 1999 г. №165-Ф3 «Об основах обязательного социального

\footnotetext{
${ }^{6}$ См., например, Захаров М.Л. Международные стандарты и российская пенсионная система // Журнал российского права. 2012. № 9. C. 5 - 18; № 10. C. $14-29$.
}

страхования $\gg^{7}$ страховой стаж - это суммарная продолжительность времени уплаты страховых взносов. Как видим, в последнем определении нет никакого указания на уплату взносов только в течение периодов трудовой или иной оплачиваемой деятельности.

В соответствии со ст.29 Федерального закона от 15 декабря 2001 г. «Об обязательном пенсионном страховании в Российской Федерации» ${ }^{8}$ возможно добровольное вступление в правоотношения по обязательному пенсионному страхованию. Например, если жена не работает, то муж может уплачивать за нее страховые взносы. Как видим, такие взносы ведь не связаны с трудовой или иной оплачиваемой деятельностью жены.

Представляется целесообразным закрепить в Законе о страховых пенсиях и Законе от трудовых пенсиях определение страхового стажа как суммарной продолжительности уплаты страховых взносов, без указания на отчисление их в период трудовой или иной оплачиваемой деятельности в целях защиты прав лиц, добровольно вступивших в правоотношения по обязательному пенсионному страхованию.

В швейцарском законодательстве упоминается полный и неполный период уплаты страховых взносов. Понятие «полный страховой стаж» означает, что лицо уплачивало страховые взносы, начиная с первого января, следующего за годом, в котором ему исполнилось 20 лет (возраста, когда неработающие лица обязаны уплачивать страховые взносы) до достижения пенсионного возраста. Таким образом, полный (максимальный) страховой стаж составляет у мужчин 44 года, у женщин - 43 года. Неполный страховой стаж является следствием перерывов в уплате страховых взносов и влечет пропорциональное недостающим годам уменьшение размера пенсии. Минимальный страховой стаж составляет один год для обоих полов, что даже меньше, чем сейчас в России, поскольку ч. 2 ст.7 Закона о трудовых пенсиях устанавливает, что для назначения трудовой пенсии по старости требуется не менее пяти лет страхового стажа.

Может показаться, что полный страховой стаж в Швейцарии очень значительный. Однако необходимо помнить, что в Швейцарии лица уплачивают страховые взносы независимо от осуществления трудовой или иной оплачиваемой деятельности.

${ }^{7}$ СЗ РФ. 1999. № 29. Ст. 3686; 2003. № 52 (часть I). Ст. 5037; 2004. № 10. Ст. 836; 2008.№ 29 (ч. 1). Ст. 3417; 2009. № 30. Ст. 3739; 2010.№ 49. Ст. 6409; 2011. № 29. Ст. 4291.

${ }^{8}$ Российская газета. 20.12.2001 № 247. 
DOI: $10.7256 / 1811-9018.2014 .5 .11979$

При цитировании этой статьи сноска на dоі обязательна

\section{Право и политика $5(173) \cdot 2014$}

Поэтому фактически речь идет о полном периоде трудоспособности гражданина.

Согласно Закону особо выделены периоды осуществления воспитательных функций в отношении одного или нескольких детей в течение 16 лет, а также ухода за нетрудоспособными родственниками. Значение учета указанных выше периодов важно, поскольку осуществляющие такие функции лица вносят важный вклад в благополучие общества и способствуют улучшению демографической ситуации в стране.

Как известно, в российском пенсионном законодательстве в страховой стаж включаются также периоды ухода за ребенком и нетрудоспособными членами семьи. Согласно ч.1 ст.11 Закона о трудовых пенсиях периоды ухода одного из родителей за каждым ребенком до достижения им возраста полутора лет берутся в большей сложности не более четырех с половиной лет, в других случаях учитывается время ухода за инвалидом I группы, ребенком-инвалидом или лицом, достигшим возраста 80 лет. Хотя ранее учитывался девятилетний период ухода за детьми по Закону Российской Федерации от 20 ноября 1990 г. № 340-1 «О государственных пенсиях в Российской Федерации» (далее - Закон от 20 ноября 1990 г. № 340-1). С учетом заложенного Законом о страховых пенсиях увеличения длительности требуемого страхового стажа, а также важности улучшения демографической ситуации в стране можно предложить учитывать девятилетней период ухода за детьми, так как необходимо, чтобы мать могла осуществлять полноценный уход за тремя детьми в возрасте до трех лет. С учетом запланированного увеличения требуемой продолжительности страхового стажа до пятнадцати лет к 2025 г., можно будет не опасаться того, что страховой стаж будет состоять только из нестраховых периодов при увеличении продолжительности учитываемого периода ухода за детьми.

Говоря об увеличении требуемого страхового стажа до пятнадцати лет по российскому законодательству, сторонники этих мер отмечают, что это позволит сделать пенсионную систему более отвечающей вкладу каждого лица, поскольку несправедливо, когда, получая минимальный размер оплаты труда и работая в течение пяти лет лицо будет получать пенсию в течение около двадцати лет ${ }^{10}$. Однако повышение требований к длительности страхового стажа до 15 лет встречает и

\footnotetext{
9 Ведомости Съезда народных депутатов РСФСР и Верховного Совета РСФСР. 1990. № 27. Ст. 351.

${ }^{10}$ Исаев А. Новые законы о пенсиях. Комсомольская правда. 2013. 21.11 .
}

критику ученых. Так, М.Л.Захаров и Э.Г.Тучкова опасаются того, что лица, страховой стаж которых менее пятнадцати лет, останутся за рамками страховой пенсионной системы, а страховые взносы, внесенные за них, будут изъяты и направлены на выплату пенсий иным гражданам, что противоречит подходу к страховым платежам как к резервируемой части их рабочей силы ${ }^{11}$.

Представляется, что принятый в Швейцарии подход к длительности страхового стажа более справедлив, поскольку, несмотря на длительный полный страховой стаж, даже при минимальном страховом стаже в один год лицам назначается страховая пенсия, размер которой в любом случае не может быть ниже, чем гарантированный законом минимум (сейчас 1170 швейцарских франков в месяц).

Рассмотрев условия назначения пенсии по старости в Швейцарии, можно сказать, что необходимый для этого юридический состав схож с предусмотренным российским законодательством. При анализе отдельных его элементов автором выявлены положительные аспекты, которые могут быть учтены российским законодателем. Совершенствованию пенсионного обеспечения могут способствовать закрепление в законодательстве целей назначения пенсий для обеспечения пенсионеру достойного уровня жизни, понятия страхового стажа без привязки к уплате страховых взносов в период трудовой или иной оплачиваемой деятельности, увеличение засчитываемого в страховой стаж периода ухода за детьми.

\section{Библиография:}

1. Carnal Pierre-Yves. Les assurances sociales, la politique sociale et la sécurité sociale: essai de définitions et de presentation générale. Aspects de la sécurité sociale. 2004. №1.

2. Борисенко Н.Ю. Пенсионное обеспечение. М., 2009.

3. Галаганов В.П. Право социального обеспечения. М., КноРУС. 2010.

4. Захаров М.Л., Тучкова Э.Г. Право социального обеспечения России. М., Бек. 2001. .,

5. Захаров М.Л. Международные стандарты и российская пенсионная система // Журнал российского права. 2012. № 9.

\footnotetext{
11 Захаров М.Л., Тучкова Э.Г. Пенсионная реформа продолжается - проблемы остаются. Материалы IX международной научнопрактической конференции. Пути реализации в России программы достойного труда и достойного социального обеспечения. Под общей ред. К.Н.Гусова. М., Проспект. 2013. С.618.
} 
6. Захаров М.Л., Тучкова Э.Г. Пенсионная реформа продолжается-проблемы остаются.// Материалы IX международной научно-практической конференции. Пути реализации в России программы достойного труда и достойного социального обеспечения. Под общей ред. К.Н.Гусова. М., Проспект. 2013.

7. Лушникова М.В., Лушников А.М. Курс права социального обеспечения. 2-е изд., доп. М.: Юстицинформ, 2009.

8. Люблин Ю.З. Пенсионная система: иное мнение. Социальное и пенсионное право. 2011. № 4.

9. Роик В.Д., Степанов Б.Г., Эченикэ Е.В. Зарубежный опыт организации и модернизации пенсионных систем: уроки для России. Москва: НПФ «Благосостояние». 2007.

10. Волков И.А. Негосударственные пенсионные фонды как предмет финансово-правового регулирования // Актуальные проблемы российского права. - 2011. - 4. - С. 92-103.

11. О. А. Ногина. Внешний и внутренний финансовый контроль в отношении формирования, распределения и использования средств бюджетов государственных внебюджетных фондов // Финансовое право и управление. - 2013. - № 2. - С. 104-107. DOI: 10.7256/2310-0508.2013.2.9881

12. Терентьева Г. В.. Новый Глобальный подход ЕС к миграции и мобильности (GAMM) и социальные аспекты миграционной политики Италии // Тренды и управление. - 2013. - № 3. - С. 104-107. DOI: 10.7256/2307-9118.2013.3.6592

13. Г.В. Терентьева. Новый Глобальный подход ЕС к миграции и мобильности (GAMM) и социальные аспекты миграционной политики Италии // Политика и Общество. - 2013. - № 4. - С. 104-107. DOI: $10.7256 / 1812-8696.2013 .04 .12$

14. Р. А. Митрофанов. Вопросы реформы пенсионной системы // Налоги и налогообложение. - 2012. № 1. - С. 104-107.

15. Н. Р. Исправникова, Д. Н. Романов. Перспективы модернизации базовых институтов социальной сферы // Политика и Общество. - 2011. - № 8. C. $104-107$.

16. Н. Р. Исправникова, Д. Н. Романов. Перспективы модернизации базовых институтов социальной сферы // Национальная безопасность / nota bene. - 2011. - № 4. - С. 104-107. Дискуссионный клуб. Страховые взносы взамен ЕСН - равноценный обмен? // Налоги и налогообложение. - 2009. - № 12 .
17. Коваль В.О.. Специфика налогообложения вкладчиков-юридических лиц при реализации договоров негосударственного пенсионного обеспечения // Налоги и налогообложение. - 2009. - № 5

\section{References (transliteration):}

1. Carnal Pierre-Yves. Les assurances sociales, la politique sociale et la sécurité sociale: essai de définitions et de presentation générale. Aspects de la sécurité sociale. 2004. №1.

2. Borisenko N.Yu. Pensionnoe obespechenie. M., 2009.

3. Galaganov V.P. Pravo sotsial'nogo obespecheniya. M., KnoRUS. 2010.

4. Zakharov M.L., Tuchkova E.G. Pravo sotsial'nogo obespecheniya Rossii. M., Bek. 2001. .,

5. Zakharov M.L. Mezhdunarodnye standarty i rossiiskaya pensionnaya sistema // Zhurnal rossiiskogo prava. 2012. № 9.

6. Zakharov M.L., Tuchkova E.G. Pensionnaya reforma prodolzhaetsya-problemy ostayutsya.// Materialy IX mezhdunarodnoi nauchno-prakticheskoi konferentsii. Puti realizatsii v Rossii programmy dostoinogo truda i dostoinogo sotsial'nogo obespecheniya. Pod obshchei red. K.N.Gusova. M., Prospekt. 2013.

7. Lushnikova M.V., Lushnikov A.M. Kurs prava sotsial'nogo obespecheniya. 2-e izd., dop. M.: Yustitsinform, 2009.

8. Lyublin Yu.Z. Pensionnaya sistema: inoe mnenie. Sotsial'noe i pensionnoe pravo. 2011. № 4.

9. Roik V.D., Stepanov B.G., Echenike E.V. Zarubezhnyi opyt organizatsii i modernizatsii pensionnykh sistem: uroki dlya Rossii. Moskva: NPF "Blagosostoyanie". 2007.

10. Volkov I.A. Negosudarstvennye pensionnye fondy kak predmet finansovo-pravovogo regulirovaniya // Aktual'nye problemy rossiiskogo prava. -2011 . -4 . - C. 92-103.

11. O. A. Nogina. Vneshnii i vnutrennii finansovyi kontrol' $\mathrm{v}$ otnoshenii formirovaniya, raspredeleniya i ispol'zovaniya sredstv byudzhetov gosudarstvennykh vnebyudzhetnykh fondov // Finansovoe pravo i upravlenie. - 2013. - № 2. - S. 104-107. DOI: 10.7256/23100508.2013.2.9881

12. Terent'eva G. V.. Novyi Global'nyi podkhod ES k migratsii i mobil'nosti (GAMM) i sotsial'nye aspekty migratsionnoi politiki Italii // Trendy i upravlenie. - 2013. - № 3. - S. 104-107. DOI: 10.7256/23079118.2013.3.6592 
DOI: 10.7256/1811-9018.2014.5.11979

При цитировании этой статьи сноска на доі обязательна

\section{Право и политика 5 (173) 2014}

13. G.V. Terent'eva. Novyi Global'nyi podkhod ES k migratsii i mobil'nosti (GAMM) i sotsial'nye aspekty migratsionnoi politiki Italii // Politika i Obshchestvo. - 2013. - № 4. - S. 104-107. DOI: 10.7256/18128696.2013.04.12

14. R. A. Mitrofanov. Voprosy reformy pensionnoi sistemy // Nalogi i nalogooblozhenie. - 2012. - № 1. - S. 104-107.

15. N. R. Ispravnikova, D. N. Romanov. Perspektivy modernizatsii bazovykh institutov sotsial'noi sfery // Politika i Obshchestvo. - 2011. - № 8. - S. 104-107.
16. N. R. Ispravnikova, D. N. Romanov. Perspektivy modernizatsii bazovykh institutov sotsial'noi sfery // Natsional'naya bezopasnost' / nota bene. - 2011. № 4. - S. 104-107. Diskussionnyi klub. Strakhovye vznosy vzamen ESN - ravnotsennyi obmen? // Nalogi i nalogooblozhenie. -2009 . - № 12.

17. Koval' V.O.. Spetsifika nalogooblozheniya vkladchikov-yuridicheskikh lits pri realizatsii dogovorov negosudarstvennogo pensionnogo obespecheniya // Nalogi i nalogooblozhenie. - 2009. - № 5 